DOI: $10.15503 /$ jecs20151.65.74

\title{
INQUIRY BASED LEARNING IN SCIENCE EDUCATION AND MATHEMATICS FOR DEVELOPING BILINGUALS
}

\section{Nataliya H. Pavlova}

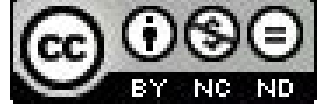

Faculty of Mathematics and Computer Science, Shumen University, 115 Universitetska Str., 9712 Shumen, Bulgaria. E-mail address: natalia_1@abv.bg

\section{Dragomir V. MarcheV}

Faculty of Natural Sciences, Shumen University, 115 Universitetska Str., 9712 Shumen, Bulgaria.

E-mail adderess: d.marchev@shu-bg.net

\section{BORISLAV ST. BORISOV}

Faculty of Natural Sciences, Shumen University, 115 Universitetska Str., 9712 Shumen, Bulgaria.

E-mail address: b.borisov@shu-bg.net

\section{Krasimir V. Harizanov}

Faculty of Mathematics and Computer Science, Shumen University, 115 Universitetska Str., 9712 Shumen, Bulgaria.

E-mail: kr.harizanov@abv.bg

\begin{abstract}
This article studies the problem of teaching bilingual children. A definition of "developing bilingual" is proposed. The article presents an example of the application of inquiry based learning through which students develop not only math skills but also lexical capabilities. This study offers levels of differentiation in different groups of students. The paper determines advantages and disadvantages of the use of Inquiry Based Learning in developing bilingual groups.
\end{abstract}

Keywords: developing bilinguals, inquiry-based learning, science education, teachers.

\section{INTRODUCTION}

Globalization in the past years led to a rapid increase of bilinguals in the developing countries. The impressive number of bilinguals in Bulgaria is not a result of the economic progress, but has historical origins. There are many regions with mixed populations and a great share of children of Turkish and Roma origin. In "Teaching Bulgarian Language in Terms of Bilingualism" Margarita Georgieva presents the interaction between Turkish and Bulgarian languages as well as a model of teaching the Bulgarian language as a second language (Georgieva, 2004). 
It is a rule that there is no problem with the language barriers in the cities when teaching bilinguals but in the villages the children often do not know Bulgarian and at this stage they cannot be referred to as bilinguals because they speak only one language - the language in which they communicate with their parents and the people around them. They are to become bilinguals in the process of study. We will refer to these children as developing bilinguals. The training of such students is often carried out by teachers from the same community and hence in the same language. This makes students' integration more difficult at a later stage and stops their development as bilinguals.

The object of the presented study are the teachers of developing bilinguals. The subject is the impact of the Inquiry Based Learning on the teaching of developing bilinguals.

The aim of the study is to determine the advantages and disadvantages of the use of Inquiry Based Learning in developing bilingual groups on the basis of expert opinion of teachers who participated in LD-skills workshops.

\section{METHODOLOGY OF RESEARCH}

In this paper we focus on the positive and negative side of using Inquiry Based Learning (IBL) in science and maths lessons with developing bilinguals. This task was part of a wider research on teachers' interest in using IBL in their science and maths classes. The survey and discussions were conducted in 2011 during a gathering of 120 teachers from Bulgaria, Germany, Greece, Turkey and other countries. The problem about using IBL for developing bilinguals was discussed with Bulgarian teachers during LD-skills workshops. The main conclusions of this study are based on the SWOT analysis of the opinions of Bulgarian teachers. The results are consistent with the members of the project consortium LD-skills.

The chosen LD-skills methodology to conduct the survey containes:

- Definition of survey's target group.

- Definition of main criteria and indicators in a form suitable to be analyzed by using a questionnaire.

- Design of research questions that cover indicators and describe a user profile.

- Detection of workshop discussion themes which could reveal the users training needs set in LD-skills objectives.

- Organization and carrying out of workshops.

- Analysis of the ideas raised during the workshops.

- Questionnaire survey with people who attended the seminars and with others via e-mails.

- Data processing with MS Excel. Determining the ratio between the responses.

- Data analysis of all indicators.

- SWOT analysis of the questionnaire results and ideas from workshop discussions.

- Conclusions. 


\section{RESEARCH RESULTS}

The surveys show that teachers are interested in inquiry based learning but share the opinion that they need training about the ideas of the inquiry and rely on finding examples of similar good practices, created and approved by their colleagues.

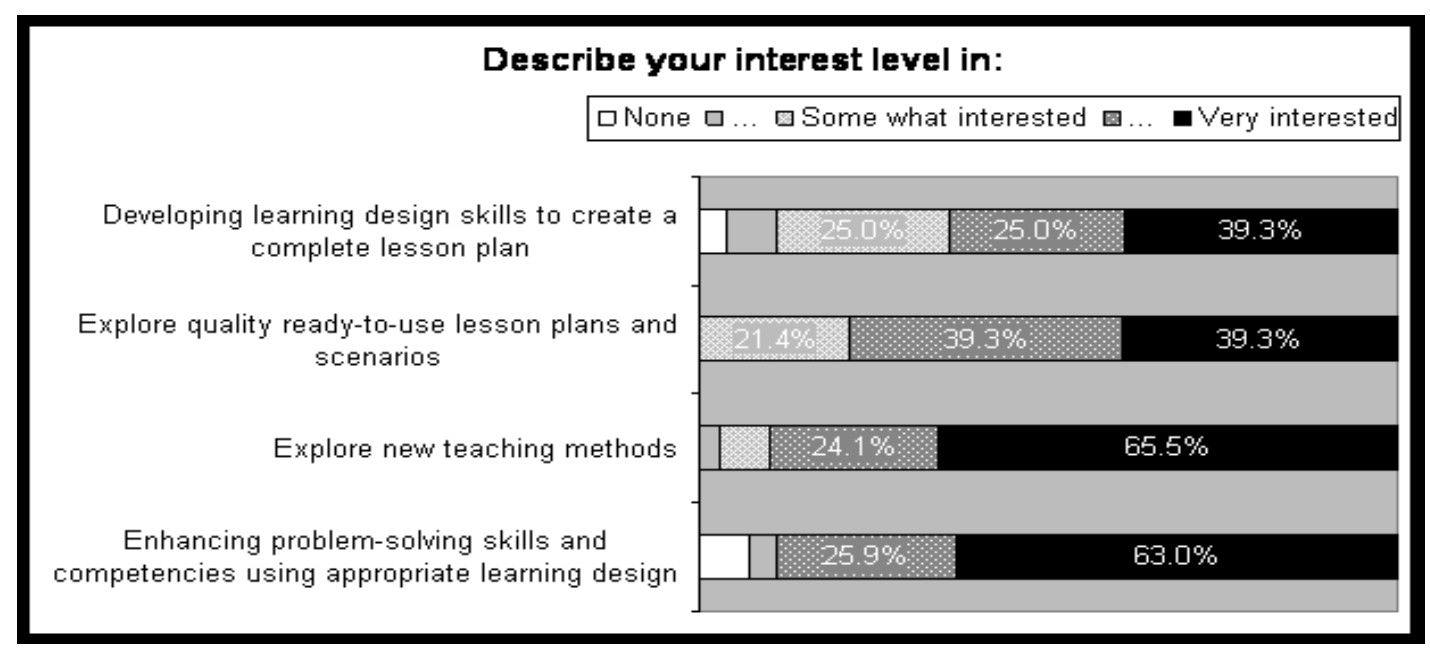

Figure 1: Teachers' interests

Source: Marchev, D., Toncheva, N., Borisov, B., Kyurkchieva, D., Radeva, V., \& Ivanova, V. (2013). D2.1 Needs Analysis Report, D2.2 European State of the Art Report, WP2 - LD-skills: Development of learning design skills for enhancing students' key competencies. Shumen: Shumen University Press.

Figure 1 shows the results about the users' interests. The survey is conducted among pre-service and in-service European teachers. Sample size is 120 (Marchev, 2013).

In Bulgarian workshops some of the common questions and issues were the following:

- What is the percentage of developing bilinguals in your class?

- Do you think the IBL will contribute to the work with developing bilinguals?

- What problems do you see in implementing IBL with developing bilinguals?

- What advantages do you see in the application of IBL with developing bilinguals?

- Is there any difference in the application of IBL with developing bilinguals and native speakers?

More results of this survey are shown in (Marchev, 2013).

\section{DISCUSSION}

There are several definitions of the term bilingualism. In this work we use Weiten's definition: "It is a skill that requires the "acquisition of two languages that use different speech sounds, vocabulary, and grammatical rules" (Weiten, 
2010, p. 323). In this definition it is clearly marked the usage of more than one language but the problem that is addressed in the current work is related to the development of bilinguals with the help of school and the multicultural environment in which the students that know more than one language are placed. The case when bilingualism is formed in the family is not an object of this work. Here we focus on the teachers that work with children who do not know or use limited lexical knowledge of the official language, namely the developing bilinguals.

Developing bilinguals we will call people who were born and live in one country but do not speak the official language and they are in the process of learning the official language of the state. This process may be while going to kindergarten, school, university, work, etc. In this paper we mainly consider developing bilingualism at school age.

The right transition to normal school work, the achievement of the main educational goals is a hard and very emotional process not only for the children but for their teachers as well. This transition is especially difficult in cases when primary school children have been taught wrongly in their mother tongue and have not mastered the official language. When they go to secondary school, they experience a real shock - in addition to the general difficulties in different subjects, they face a serious language barrier. Teachers are not less affected. In such mixed classes they need to organize various differentiation levels.

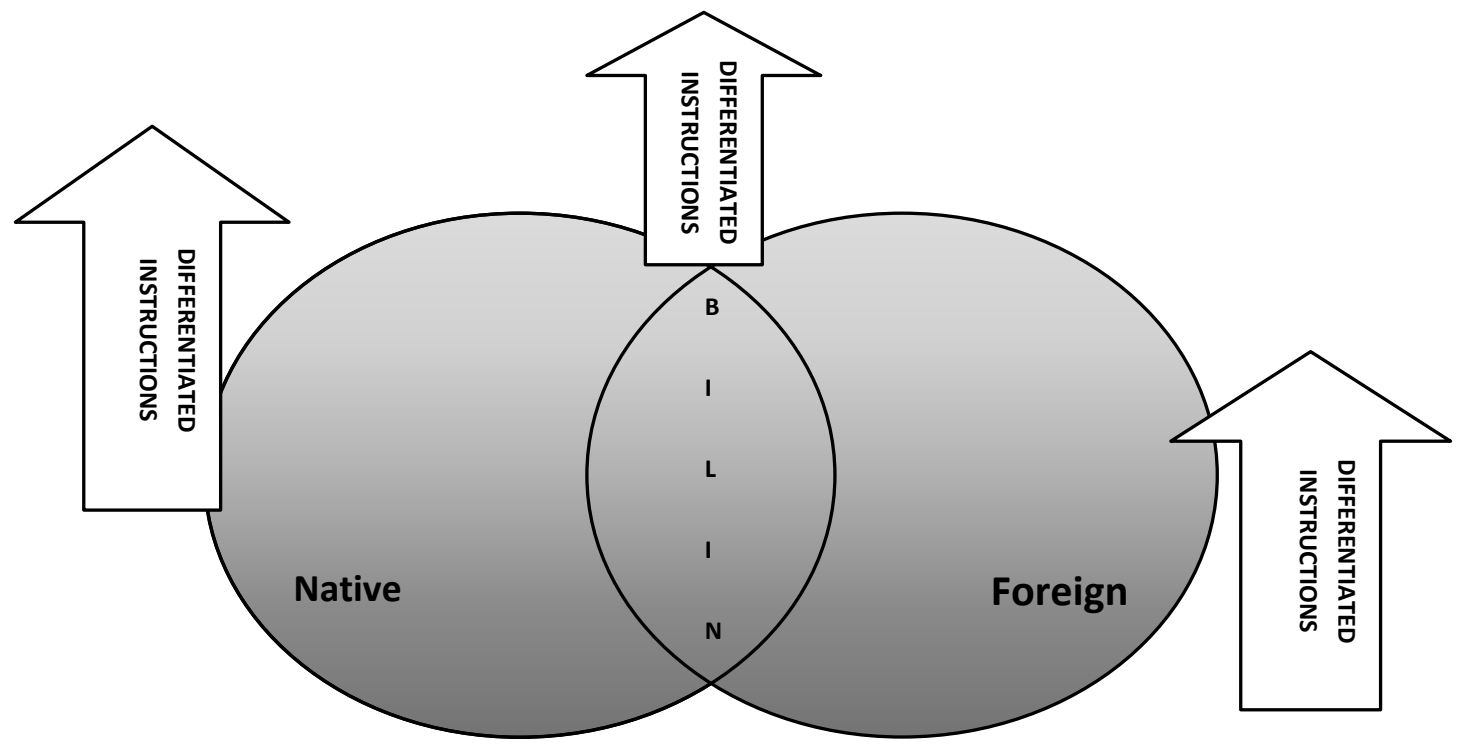

Figure 2: Differentiation Levels Source: Own research

The differentiation on a particular subject is modeled in Figure 2 using dark blue color. Besides the expected differentiations (depending on the motivation to work, the level of knowledge, the specific skills) there is a need for a division into three groups - speaking only the official language, speaking only the language of the given community and bilinguals. Conduct of such training is an extremely demanding process, and teachers share their concerns about its implementation. They understand that the students are developing bilinguals in this situation. 
Hence, the teachers should be active participants in the creation of bilinguals.

A methodological system for teaching the Bulgarian language in terms of Turkish-Bulgarian bilingualism is shown in (Georgieva, 2004). Language specialists are prepared to cope with this problem to some degree but teachers of mathematics and science are facing a real dilemma. Besides achieving the complicated educational goals of theirs subjects and introducing the students to the specific terminology they have to deal with the language barrier. One solution of this problem is to implement inquiry based teaching in these classes.

The idea to acquire knowledge through inquiry based learning approach is not new but it gained popularity after the report of Rocard (Rocard, 2007). The widespread decline in the interest of children towards subjects of natural sciences and mathematics, has challenged methodologists to emphasize the way of learning in which a student is a leading figure and knowledge is largely acquired independently by the student rather than being presented by the teacher. The teacher plays a new role - a mentor, supplying and verifying knowledge and skills. $\mathrm{He} /$ she becomes a leader and a guide of the students on their way to knowledge.

A number of educational projects undertook the development of a methodology for inquiry based learning, promotion of best practices, creation of repositories of educational resources in addition to the given approach. The excellent results of teaching by inquiry are already established in the project COSMOS (Marchev, 2010). With the help of extensive surveys of teachers related to a number of active methods it is found that training through inquiry is the best method approved by teachers and they give their efforts to use it more often with their students. To date there are a number of portals that offer quality educational resources and can be used free of charge by all teachers and students. Here we mention two of them. They have a proven effect on the implementation of inquiry based learning and are available in several European languages:

- www.osrportal.eu - a portal containing variable materials related mainly to training in natural sciences

- http://www.cosmosportal.eu - a portal containing a large number of images and lessons related mainly to training in physics and astronomy.

Besides learning depositories with educational resources specially designed to be used in the Pan-European area there are a number of portals popular in different European countries. In accordance with "European State of the Art Report" (Marchev, 2013) some of the most popular educational portals at local level are as follows:

- www.enseignement.be - It collects curriculum-based news, features teacher training opportunities and provides external links to existing repositories with learning objects in French speaking states.

- www.klascement.net - This portal is a part of European Schoolnet's Learning Resource Exchange (LRE) federation of repositories. All KlasCement content is collected, described and shared by users of the educational portal of Flanders in Belgium. It covers virtually all curriculum subjects and can be freely used by anyone. 
- http://start.e-edu.bg - Bulgarian National Portal offers to the users ready didactic materials and pathways, educational documents, forums, list of schools, news, etc. The audience of this portal consists mainly of teachers and students. All subjects and educational levels are included.

- http://www.sch.gr - The Greek national school repository is the national school portal of Greece, maintained and operated by RACTI. The repository will be further enriched by large national initiative "Digital School", that is going to populate it with open educational resources, open textbooks, teacher-generated materials, cultural content of educational interest, etc. The repository is supported and promoted by the Greek Ministry of Education, Lifelong Learning, and Religious Affairs.

- http:/ / www.e-yliko.gr - This action aims to support the learning community by providing digital learning resources online.

- www.fenokulu.net - This portal includes science units, experiments, flash animations, exams, pictures, projects and mind maps for 6, 7, 8 grades. At the same time, there are elementary science and technology curricula for the same grades. Students enter this site, watch animations, do experiments and exams and teachers can use this site as the beginning and ending of their lessons.

- http://www.fenci.gen.tr-This portal includes exams, science lesson plans, science presentations, science projects, experiments, animations, pictures, videos, teachers' presentations, simulations, pictures in 3D, e-games about science and science content. There is also member entrance in this portal and members add and share annual plans, exams, videos and animations. 1799 files, 849 documents, 153 news, 406 videos, 969 animations, 437 pictures, 143 additional exams are available.

Besides the opportunity to use and share didactical materials with the help of portals teachers also need training. Workshops are held in the framework of educational projects, such as GEOTHiNK (Kavouras, 2013), Pathway (Bogner, \& Sotiriou, 2012), LD - skills (Tzikopoulos, 2010) etc.

\section{EXAMPLE}

In the example we shall use the structure of the GEOTHiNK project (Figure 3). We will give a short example for a similar training on the topic "Rotating Bodies" for mathematics lessons in the $6^{\text {th }}$ grade. Similar description of the given lesson with a simulation of a science museum visit where the students search for rotating bodies and related help files can be found at: http:/ / www.osrportal.eu/ en/node/96045. A general approach and different options for using Google SketchUp are described In "Google SketchUp as a Tool of Computer Assisted Learning in Different Subjects" (Toncheva, 2011). "Visit" in this case is observing the simulation of rotation in $3 \mathrm{D}$. 


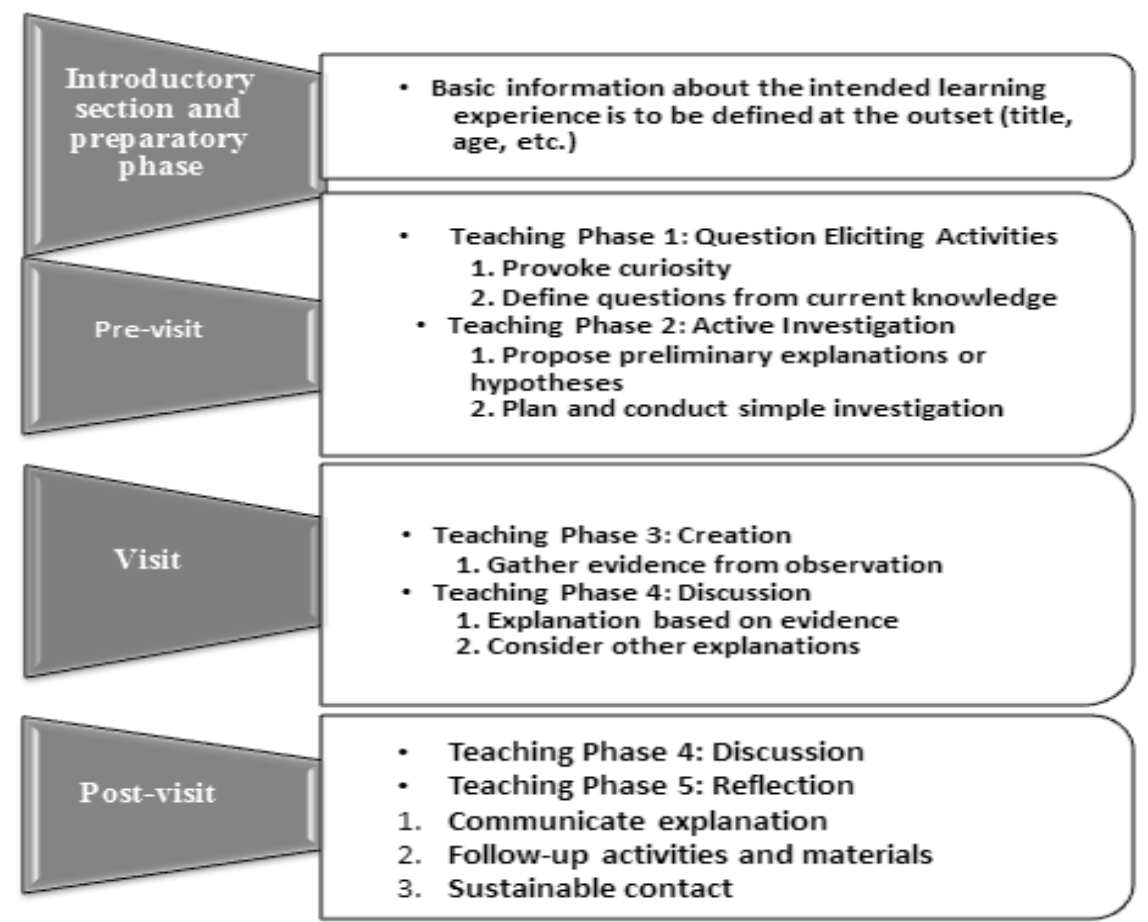

Figure 3: The educational pathway structure for students

Source: Kavouras, M. (2013). Semantic pathways for building a spatially-thinking society. Athens: Project proposal.

Students aged 11-13 years experience the so-called by psychologists "second birth". At this age children look for their self, look for their social group and their place in the group. Children are irritable. They often change their attitudes, priorities and interests. Interest in mathematics in this age group is not usually high. As an overlay we can see the problem with the development of bilingualism, and we will understand the challenge that teachers working with these children are facing .

In this lesson the teacher demonstrates how to create rotating bodies using Google SketchUp. The students understand the process but the term "rotation" is unfamiliar to all children. There is no need for the teacher and the children to know all the possibilities of the software. Just a few more tools are necessary. They are described in the final tutorial mentioned above. A help file is also available there. A screenshot of a file is presented in Figure 4. 


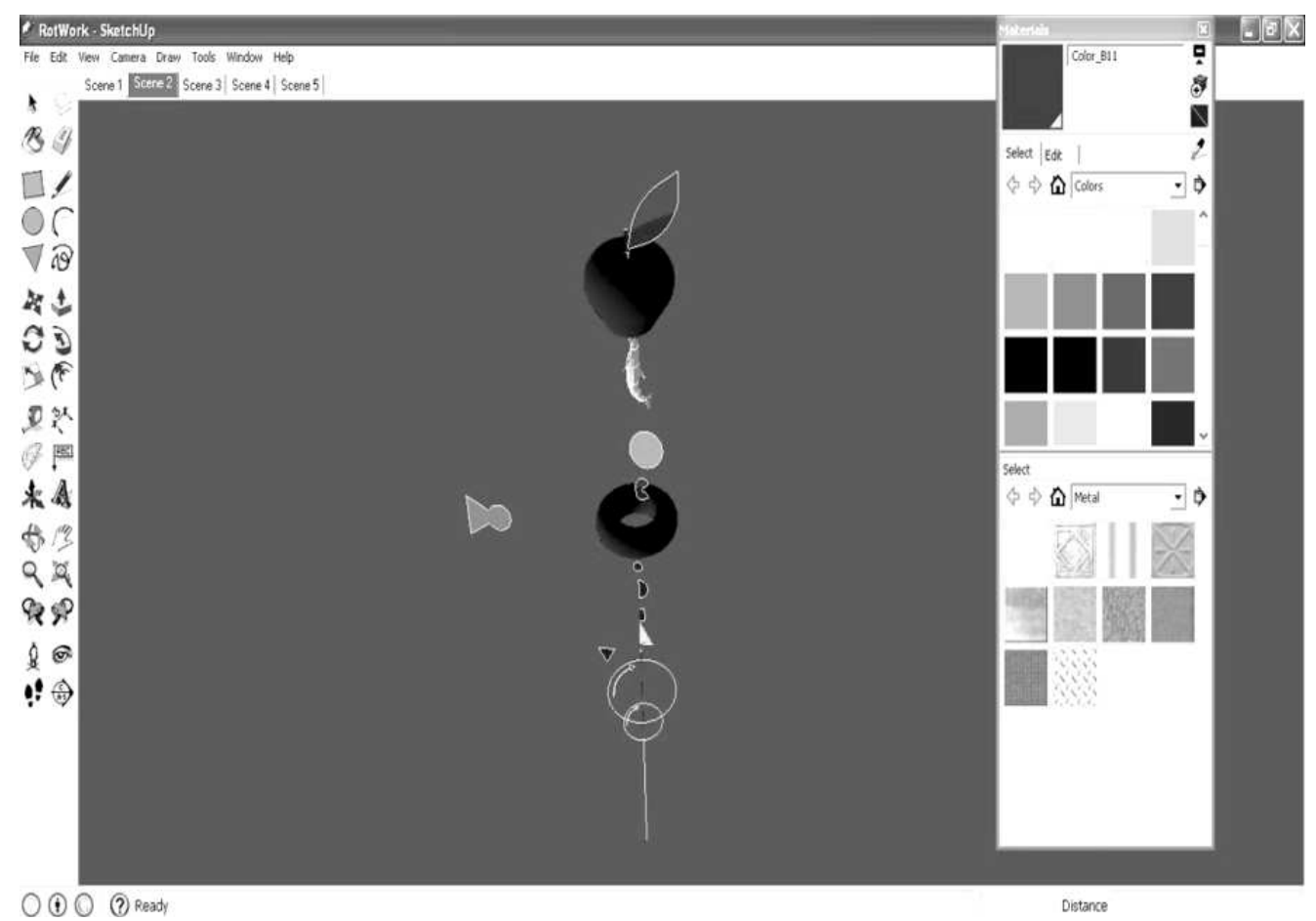

Figure 4: Supporting file for "Rotating Bodies"

Source: Toncheva, N. (2011). Google SketchUp as a Tool of Computer Assisted Learning in Different Subjects, Journal of International Scientific Publication: Education, Researches \& Development, 9 (2), 142-155

The teacher "rotates" the figures using the help file and introduces the term rotating body. All students are placed on an equal footing.

The introduction is followed by the task for finding rotating bodies in everyday life. After several examples are given by their classmates the developing bilinguals can also give their own examples - orally or by demonstration - in these processes the children also learn new words.

Then students create models using the help file. All of them work and there are no language barriers for the given task.

After that each student should create an attractive model by himself/herself to be submitted to a competition. This task can be assigned for homework if all students have computers! Another option is to take time from the lesson to allow all to participate in the competition using school facilities.

The competition - here they reach the most emotional stage where everyone brings his/her model. One student presents his/her model and the other students guess what is depicted in the file. All of them discuss and evaluate the model. For the developing bilinguals this is the place where they must comment on their models and those of their classmates. After the accumulated lexical set of comments from the native language speakers, it will be easier for them to describe their models.

An additional moment in this lesson is the interest which the students have towards Google SketchUp. There is a huge possibility that they may continue to work with it independently at home and train their friends, brothers and sisters. In this process the students make connection between the two languages which is particularly important for their development as bilinguals. 
The given lesson is not hard for the teacher to teach - the only requirement is some spare time to master several instruments of Google SketchUp. The lesson timing may vary according to the choice of the teacher to demonstrate only the creation of rotating bodies or to give an opportunity for the students to design and share their models. In most schools there are technologically well equipped facilities and the technical part should not be a problem. But still, if there is no possibility to use a computer laboratory, it is possible to present the new knowledge with a projector and laptop.

\section{CONCLUSIONS}

Inquiry-based learning (IBL) in developing bilinguals:

- As shown in Figure 2, the teacher who develops bilinguals faces the language barrier in addition to the standard didactic task. One way to ease the overcoming of this barrier is precisely learning through the process of inquiry. By participating in an experiment and seeing its results, students understand the concept of a lesson more easily than in the form of a lecture. Besides the general benefits of IBL typical for all students - increased interest and motivation, longevity of knowledge, we highlight some specific accents to developing bilinguals with the help of IBL. The strengths and weaknesses typical for the development of bilinguals are described above.

Advantages:

- The students "see" and "do" knowledge without the need of extensive lexical stock.

- If a student does not understand the technical algorithm of the experiment, he/she can work in a team with a native language speaker and repeat his/ her actions.

- During teamwork the students discuss various issues that also stimulate the formation of language skills.

- The experiment and all "visible" objects, outcomes, processes, phenomena are described terminologically and lexically. This approach facilitates the creation of bilinguals.

- The level of knowledge of the specific terminology of developing bilinguals does not differ from the one of the native language speakers, i.e. when children learn new words together (in this case specific terms) and this gives positive attitude and motivates bilinguals.

- The emotional power of inquiry based learning stimulates students to share their experiences (attractive chemistry experiments, astronomical observations, etc.) in the family. Thus they make a link between the official language and the language they use in the family environment.

Disadvantages:

- Not enough native language speakers to form teams in regions with a large number of developing bilinguals.

- Less general motivation to work in such groups. 
Despite the globalization of the modern world the problem with the unformed bilinguals is more and more widely spread. These children are victims of the lack of interest of the family environment to prepare competitive individuals. The school is the only path for leading them to integration. Teachers in turn are not prepared or motivated enough to deal with this problem. It is important to support them in this difficult task. IBL appears to be a suitable approach to integrate bilinguals. Teachers can acquire and improve it during the workshops held under the framework of educational projects or self-study, using the resources available on the Internet.

\section{ACKNOWLEDGEMENTS}

The research presented in this paper is partially funded by the European Commission and more specifically by the project 510276-LLP-1-2010-1-GR-COMENIUS-CMP “LD-skills: Development of learning design skills for enhancing students' key competencies" of the Comenius Programme, project 543451-LLP1-2013-1-GR-KA3-KA3MP, ,GEOTHNK: Semantic pathways for building a spatially-thinking society", (2013-2015) and the project of Scientific Foundation of Shumen University (2015).

\section{REFERENCES}

Bogner, F., \& Sotiriou, S. (2010). Project Proposal: The Pathway to Inquiry Based Science Teaching. Athens: Project proposal.

Georgieva, M. (2004). Обучението по български език в условия на билингвизъм [Teaching Bulgarian Language in Terms of Bilingualism]. Shumen: Shumen University Press.

Kavouras, M. (2013). Semantic pathways for building a spatially-thinking society. Athens: Project proposal.

Marchev, D., Kjurkchieva, D., Borisov, B., \& Radeva, V. (2010). Bulgarian Activities in the Project COSMOS: An Advanced Scientific Repository for Science Teaching and Learning. PAOB, 90, 213-216.

Marchev, D., Toncheva, N., Borisov, B., Kyurkchieva, D., Radeva, V., \& Ivanova, V. (2013). D2.1 Needs Analysis Report, D2.2 European State of the Art Report, WP2 - LD-skills: Development of learning design skills for enhancing students' key competencies. Shumen: Shumen University Press, ISBN: 978-954-577-658-8.

Rocard, M., Csermely, P., Jorde, D., Lenzen, D., Walberg-Henriksson, H., \& Hemmoet, V. (2007). Science Education NOW: A Renewed Pedagogy for the Future of Europe. Luxembourg: Office for Official Publications of the European Communities.

Toncheva, N. (2011). Google SketchUp as a Tool of Computer Assisted Learning in Different Subjects, Journal of International Scientific Publication: Education, Researches E Development, 9 (2), 142-155

Tzikopoulos, A. (2010). Project Proposal: LD-skills: Development of learning design skills for enhancing students' key competencies, Athens: Project proposal.

Weiten, W. (2010). Psychology: Themes and variations. California: Wadsworth Cengage Learning. 